Article

\title{
Predictive Control Method Based on Adjacent Vector Confinement Technique for a Three-Phase AC-DC Matrix Converter with High Efficiency
}

\author{
Eun-Su Jun, Hoang-Long Dang and Sangshin Kwak *(D) \\ School of Electrical and Electronics Engineering, Chung-Ang University, Heukseok-dong, Dongjak-gu, \\ Seoul 06974, Korea; elizame3@naver.com (E.-S.J.); danghoanglong2692@gmail.com (H.-L.D.) \\ * Correspondence: sskwak@cau.ac.kr; Tel.: +82-2-820-5346
}

Received: 23 November 2019; Accepted: 8 December 2019; Published: 12 December 2019

\begin{abstract}
A model predictive current control method is proposed to reduce switching losses in an AC-DC matrix converter. In the proposed control strategy, several vectors are selected from among all possible switching vectors for a given location of the input current reference. The switching vector that minimizes the cost function is applied to the converter in the next sampling period. The principle of the proposed method involves clamping the selected switches to stop performing the switching operation to minimize the number of switchings in every sampling cycle. The total efficiency of the AC-DC matrix converter under the proposed strategy is $91.2 \%$ whereas that of the conventional strategy is $89.7 \%$. In addition, unity-power-factor operation is guaranteed and smooth and sinusoidal waveforms are achieved. Finally, simulation and experimental results are demonstrated to confirm the validity of the proposed control strategy.
\end{abstract}

Keywords: AC-DC matrix converter; model predictive control; switching losses

\section{Introduction}

Recently, AC-DC matrix converters (MCs), derived from the well-known MCs, have garnered considerable attention as a new type of converter [1-4]. They have various inherent advantages of MCs, such as four-quadrant operation, controllable input power factor, sinusoidal input current, compact design, and high-power density [5]. Generally, an AC-DC MC is a one-stage bidirectional current-source buck-type rectifier. It is widely applied in various areas, such as AC-DC micro-grids, electric vehicles, renewable energy generation, and battery energy storage systems [6-8]. Several modulation methods have been successfully adapted to the AC-DC MCs [9]. An AC-DC MC is traditionally controlled by a space vector modulation algorithm [10-17]. Literature [10] presents a digitally controlled power supply for isolated three-phase AC-DC MCs without modulation blocks. An ultra-sparse matrix rectifier with a unity power factor fuzzy battery charger is illustrated in Reference [11] with a reduction in the number of power semiconductor devices; however, this converter is not a bidirectional converter. Modulation and control schemes for the battery energy storage systems are studied in [12,13]. In Reference [14], a modulation strategy is proposed to reduce switching losses by optimizing the switching patterns. DC current ripple reduction algorithms are studied in References [15,16]. Application of the virtual capacitor concept to the AC-DC MCs to control the input power factor is presented in Reference [17]. Recent studies have shown the massive potential of model predictive control (MPC) thanks to the advanced development of fast and powerful digital microprocessors and power devices $[18,19]$. There are numerous advantages of MPCs over conventional modulation and control strategies, such as multiple control targets with only one cost function, simple implementation for experiments on digital control boards, the ability to include multiple constraints of the system, and a fast dynamic 
response performance. The MPC algorithm has been successfully applied to the AC-DC MCs in the literature [20-22]. Model predictive control strategies under unbalanced grid voltages have been studied [20,21]. Literature [22] investigates a unity-input-power-factor scheme for the AC-DC MCs. At each sampling period, the MPC algorithm considers all the possible switching states of an AC-DC MC generated by nine current vectors, predicts the future behaviors of input and output currents, and finally chooses the optimum switching state; this minimizing the cost function applied to the converter in the next sampling cycle.

In this study, a model predictive current control (MPCC) to reduce switching losses in AC-DC MCs is proposed. Efficiency is one of the most critical control issues in industrial applications. AC-DC MCs are widely employed in various industrial applications. Thus, it is desirable to increase the efficiency of the AC-DC MCs. Reducing the switching loss is the most popular solution for increasing the efficiency of an AC-DC MC. The desirable commutation between different switching states is the minimum for the switching number to achieve the purpose of high efficiency. The MPCC algorithm is based on the concept of finite control set model predictive control (FCS-MPC). The main principle of the proposed strategy is to clamp the switches for a given location of input current reference to stop performing the switching operation during every sampling period. This can prevent undesirable switching operations. In the proposed method, several current vectors are selected from among the nine possible current vectors regarding the location of the input current reference in the stationary vector plane to clamp the switches to stop performing the switching operation during every sampling interval. The proposed scheme enables only three current vectors to be chosen in every period. This leads to a reduction in the computation burden. Therefore, the proposed method can increase the efficiency and guarantee the performance of the converter, including the quality of input and output waveforms. Simulation and experimental results are illustrated to validate the proposed MPCC for the reduction of switching loss in the AC-DC MCs. This paper is organized as follows: in Section 2, the structure and models of the AC-DC MC are presented. The principle, the cost function, and the control scheme of the proposed control strategy are demonstrated in Section 3. The effectiveness of the proposed method is verified by simulation and experiment results in Section 4 . Section 5 presents the conclusions of this paper.

\section{AC-DC Matrix Converter}

\subsection{Structure of an AC-DC Matrix Converter}

An AC-DC MC is illustrated in Figure 1. It is constructed from six bidirectional power semiconductor devices. Generally, two insulated-gate bipolar transistors (IGBTs) with a common emitter configuration connected in series are used to construct one bidirectional switch. The operation of the AC-DC MC and the grid usually generates a high-frequency harmonic; hence, an LC filter is adapted to attenuate the undesirable harmonic. To maintain the high quality of output waveforms, an output filter is applied at the output terminal. The AC-DC MC is utilized by a three-phase voltage source; thus, the three-phase voltages cannot be shorted. Additionally, the load of the AC-DC MC is mainly inductive, and the output side is not allowed to be opened. Hence, in the operation of the AC-DC MC, only one bidirectional power device is connected in the positive three-phase legs and only one bidirectional power device is connected in the negative three-phase legs at any instant. Therefore, there are nine possible switching states in the operation of the AC-DC MC. In Figure $1, v_{s a}, v_{s b}, v_{s c}$ are the three-phase source voltages, and $v_{i a}, v_{i b}, v_{i c}$ are the three-phase input voltages. $i_{s a}, i_{s b}, i_{s c}$ are the three-phase source currents, and $i_{i a}, i_{i b}, i_{i c}$ are the three-phase input currents. Whereas $R_{f}, L_{f}, C_{f}$ are the input filter resistors, the input filter inductors, and the input filter capacitors, respectively. At the output side, $V_{B a t}, V_{d c}, i_{d c}$ are the load voltage, the DC voltage and DC current, respectively. Whereas $L, C$ are the output filter inductor and the output filter capacitor, respectively. Finally, $S_{p a}, S_{p b}, S_{p c}, S_{n a}, S_{n b}, S_{n c}$ are the bidirectional switches of the AC-DC matrix converter. 


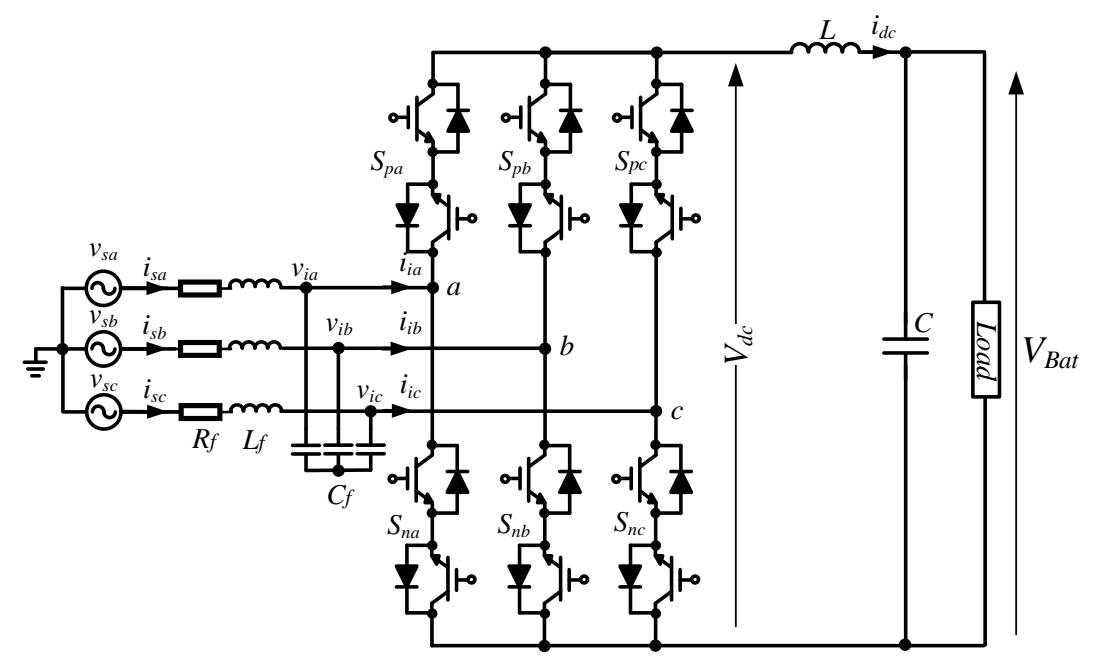

Figure 1. AC-DC matrix converter (MC).

\subsection{Continuous-Time Model of the AC-DC Matrix Converter}

The input currents of the converter are expressed as a function of the bidirectional power devices and DC current, and the DC voltage is generated by the bidirectional power devices and three-phase input voltage as

$$
\begin{gathered}
i_{i}=S i_{d c} \\
V_{d c}=S^{T} v_{i} \\
S=\left[\begin{array}{l}
S_{p a}-S_{n a} \\
S_{p b}-S_{n b} \\
S_{p c}-S_{n c}
\end{array}\right]
\end{gathered}
$$

where

$i_{i} \quad$ Input currents $\quad\left[i_{i a} i_{i b} i_{i c}\right]^{T}$

$v_{i} \quad$ Input voltages $\left[v_{i a} v_{i b} v_{i c}\right]^{T}$

$S$ Switches matrix

The input filter model of the converter is expressed as

$$
\begin{gathered}
v_{s}=R_{f} i_{s}+L_{f} \frac{d i_{s}}{d t}+v_{i} \\
i_{s}=C_{f} \frac{d v_{i}}{d t}+i_{i}
\end{gathered}
$$

where

$v_{s} \quad$ Source voltages $\quad\left[\begin{array}{lll}v_{s a} & v_{s b} & v_{s c}\end{array}\right]^{T}$

$i_{s} \quad$ Source currents $\left[\begin{array}{lll}i_{s a} & i_{s b} & i_{s c}\end{array}\right]^{T}$

\subsection{Discrete-Time Model of AC-DC Matrix Converter}

The above equations provide the basis for the predictive model calculation of the input currents, which is considered using the cost function. Since the MPC concept is formulated in discrete time, it is desirable to derive a discrete-time model for the AC-DC MC. The input filter side can be represented by a state-space model, with the state variables $\dot{i}_{s}$ and $\dot{v}_{i}$ obtained from (4) and (5) as follows [19]:

$$
\left[\begin{array}{c}
\dot{v}_{i} \\
\dot{i}_{S}
\end{array}\right]=A\left[\begin{array}{c}
v_{i} \\
i_{s}
\end{array}\right]+B\left[\begin{array}{c}
v_{S} \\
i_{i}
\end{array}\right]
$$


where

$$
\begin{gathered}
A=\left[\begin{array}{cc}
0 & \frac{1}{C_{f}} \\
\frac{-1}{L_{f}} & \frac{-R_{f}}{L_{f}}
\end{array}\right] \\
B=\left[\begin{array}{cc}
0 & \frac{-1}{C_{f}} \\
\frac{1}{L_{f}} & 0
\end{array}\right]
\end{gathered}
$$

The discrete-time state-space model is expressed as

$$
\left[\begin{array}{c}
v_{i}(k+1) \\
i_{s}(k+1)
\end{array}\right]=\Phi\left[\begin{array}{c}
v_{i}(k) \\
i_{s}(k)
\end{array}\right]+\Gamma\left[\begin{array}{c}
v_{s}(k) \\
i_{i}(k)
\end{array}\right]
$$

where

$$
\begin{gathered}
\Phi=e^{A T_{s}} \\
\Gamma=A^{-1}\left(\Phi-I_{2 \times 2}\right) B .
\end{gathered}
$$

\section{$T_{s}$ Sampling period}

The prediction of the source current is obtained from the state-space model [23] as follows:

$$
i_{s}(k+1)=c_{1} v_{s}(k)+c_{2} v_{i}(k)+c_{3} i_{s}(k)+c_{4} i_{i}(k)
$$

where the coefficients $c_{1}, c_{2}, c_{3}$, and $c_{4}$ are computed from (10) and (11) under the assumption that $R_{f}$ is neglected owing to its small value:

$$
\begin{gathered}
c_{1}=\sqrt{\frac{C_{f}}{L_{f}}} \sin \left(\frac{T_{s}}{\sqrt{C_{f} L_{f}}}\right) \\
c_{2}=-c_{1} \\
c_{3}=\cos \left(\frac{T_{s}}{\sqrt{C_{f} L_{f}}}\right) \\
c_{4}=1-c_{3}
\end{gathered}
$$

\section{Proposed Model Predictive Current Control}

\subsection{Principle of the Proposed Method}

Achieving high efficiency with reduced switching loss is one of the most critical control problems of the AC-DC MCs. In the operation of the AC-DC MC, the switching losses when changing from one switching state to another among the nine current vectors are unequal in every sampling period. The conventional MPC considers all the possible switching states of the converter and chooses the switching state that minimizes the cost function, which is applied to the converter in the next sampling period. Simulation results of the AC-DC MC using the conventional MPC are presented in Figure 2. The parameters are chosen based on reference [24] for the equity comparison between the AC-DC MC and the voltage source rectifier (VSR) using the conventional MPC. As shown in Figure 2, the AC-DC MC performs the high-quality input and output waveforms by applying the conventional MPC. The three-phase currents of the AC-DC MC are sinusoidal and in phase with the source voltage, which guarantees the unity-power-factor operation. At the output, the pure DC voltages accurately track their references. Tables 1 and 2 show the number of the selected vectors in different sectors of the AC-DC 
MC and the VSR using the conventional MPC at the same sampling frequency, respectively. It can be observed from the tables that the number of the total selected vectors in both the VSR and AC-DC MC are almost the same; however, there are several selected vectors located outside the optimal sector, which leads to the commutations between non-adjacent vectors in each sector of both the AC-DC MC and VSR.
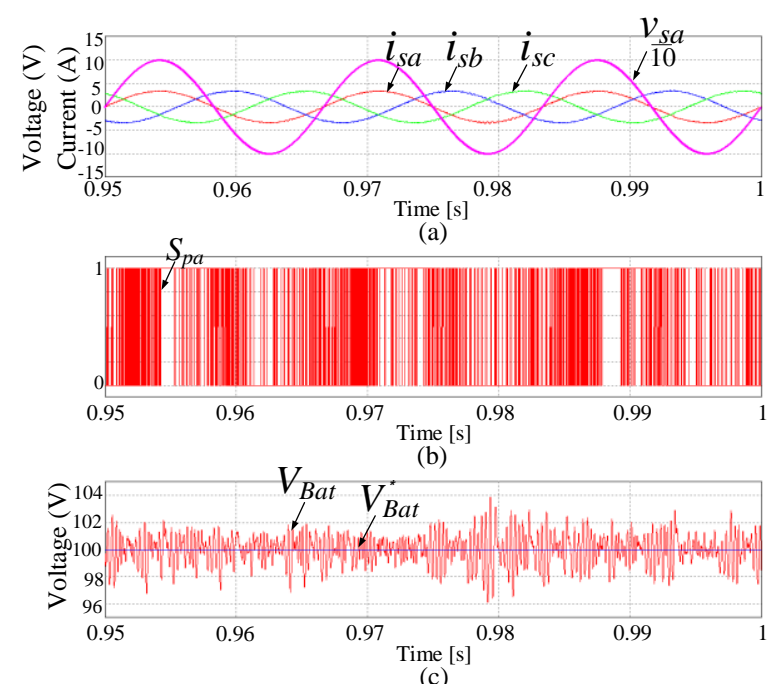

Figure 2. Simulation waveforms of the AC-DC MC using the conventional model predictive control (MPC) (a) Three-phase current, A-phase source voltage (b) switching signal (c) load voltage, and load voltage reference.

Table 1. Summary of the selected vectors in different sectors of the AC-DC matrix converter (MC) using the conventional model predictive control (MPC).

\begin{tabular}{ccccccccc}
\hline \multirow{2}{*}{ Sector } & \multicolumn{7}{c}{ Selected Vectors } & \multirow{2}{*}{ Sum } \\
\cline { 2 - 7 } & $\overrightarrow{\boldsymbol{I}}_{1}$ & $\overrightarrow{\boldsymbol{I}}_{2}$ & $\overrightarrow{\boldsymbol{I}}_{3}$ & $\overrightarrow{\boldsymbol{I}}_{4}$ & $\overrightarrow{\boldsymbol{I}}_{5}$ & $\overrightarrow{\boldsymbol{I}}_{6}$ & $\overrightarrow{\boldsymbol{I}}_{7}, \overrightarrow{\boldsymbol{I}}_{8}, \overrightarrow{\boldsymbol{I}}_{9}$ & \\
\hline 1 & 54.5 & 28.8 & 10.2 & 0 & 0 & 1 & 16.8 & 111.3 \\
2 & 1.2 & 53.8 & 29 & 9.7 & 0 & 0 & 17.7 & 111.4 \\
3 & 0 & 0.7 & 53.5 & 29.8 & 8.7 & 0 & 18.3 & 111 \\
4 & 0 & 0 & 1 & 54.5 & 28.8 & 10.5 & 16.5 & 111.3 \\
5 & 10.2 & 0 & 0 & 1.2 & 54 & 28.2 & 17.8 & 111.4 \\
6 & 29.8 & 8.8 & 0 & 0 & 1.2 & 53.3 & 18 & 111.1 \\
Sum & 95.7 & 92.1 & 93.7 & 95.2 & 92.7 & 93 & 105.1 & 667.5 \\
\hline
\end{tabular}

adjacent vector.

Table 2. Summary of the selected vectors in different sectors of the voltage source rectifier (VSR) using the conventional MPC.

\begin{tabular}{ccccccccc}
\hline \multirow{2}{*}{ Sector } & \multicolumn{7}{c}{ Selected Vectors } & \multicolumn{2}{c}{ Sum } \\
\cline { 2 - 7 } & $\overrightarrow{\boldsymbol{V}}_{1}$ & $\overrightarrow{\boldsymbol{V}}_{2}$ & $\overrightarrow{\boldsymbol{V}}_{3}$ & $\overrightarrow{\boldsymbol{V}}_{4}$ & $\overrightarrow{\boldsymbol{V}}_{5}$ & $\overrightarrow{\boldsymbol{V}}_{6}$ & $\overrightarrow{\boldsymbol{V}}_{7}, \overrightarrow{\boldsymbol{V}}_{8}$ & \\
\hline 1 & 49 & 37 & 0 & 0 & 0 & 4.2 & 21 & 111.2 \\
2 & 1.8 & 52.2 & 32.7 & 0 & 0 & 0 & 23.8 & 110.5 \\
3 & 0 & 1.2 & 52.8 & 33.5 & 1 & 0 & 22.8 & 111.3 \\
4 & 0 & 0 & 4.2 & 48.7 & 38.7 & 0 & 19.5 & 111.2 \\
5 & 0 & 0 & 0 & 0.8 & 52 & 35.3 & 23.8 & 111.9 \\
6 & 34.5 & 0.2 & 0 & 0 & 1.3 & 51.5 & 23.7 & 111.2 \\
Sum & 85.3 & 90.6 & 89.7 & 83.1 & 93 & 91 & 134.6 & 667.3 \\
\hline
\end{tabular}


The commutation between adjacent vectors located in the same sector of both the VSR and AC-DC MC involve only two switches: one switch is turned on and the other switch is turned off simultaneously. The commutations between non-adjacent vectors lead to the increase in the switching number, which results in an increase in the total loss of the switches in the VSR and AC-DC MC. Tables 3 and 4 present the percentages of the selected vectors in different sectors of the AC-DC MC and VSR using the conventional MPC, respectively. It is evident that the percentage of the use of vectors located outside the optimal sector in the AC-DC MC is much higher than that in the VSR. Figure 3 presents the commutation space vector diagram in sector I of the AC-DC MC. The switching number required for the commutation between non-adjacent vectors is four, whereas that for the commutation between adjacent vectors is only two. It is desirable to use only vectors located in sector I for the minimization of switching number. Tables 5 and 6 show the switching numbers of commutations between different vectors in different sectors of the AC-DC MC and VSR. Vectors $\vec{I}_{0}$ and $\vec{V}_{0}$ represent the zero vectors $\vec{I}_{7}, \vec{I}_{8}, \vec{I}_{9}$ and $\vec{V}_{7}, \vec{V}_{8}$ in the AC-DC MC and VSR, respectively. While the commutation in the VSR is mainly between adjacent vectors, the number of commutations between non-adjacent vectors in the AC-DC MC is much higher. This results in an increase in the switching number of each bidirectional switch in the AC-DC MC. Thus, the increase in the switching number and the switching losses owing to the commutations between non-adjacent vectors lead to undesirable losses in the AC-DC MC. To overcome these undesirable switching losses, this paper proposes an MPCC method with vector selection from among all valid switching states, and then chooses the optimum switching state based on the cost function and applies it to the converter. The principle of the proposed strategy involves selecting a set of vectors before applying the MPC algorithm to avoid the commutations between non-adjacent vectors in each sector.

Table 3. Percentage of the selected vectors in different sectors of the AC-DC MC using the conventional MPC.

\begin{tabular}{|c|c|c|c|c|c|c|c|c|}
\hline \multirow{2}{*}{ Sector } & \multicolumn{7}{|c|}{ Selected Vectors } & \multirow{2}{*}{ Sum } \\
\hline & $\vec{I}_{1}$ & $\vec{I}_{2}$ & $\vec{I}_{3}$ & $\vec{I}_{4}$ & $\vec{I}_{5}$ & $\vec{I}_{6}$ & $\vec{I}_{7}, \vec{I}_{8}, \vec{I}_{9}$ & \\
\hline 1 & $49 \%$ & $25.9 \%$ & $9.2 \%$ & 0 & 0 & $0.9 \%$ & $15 \%$ & $100 \%$ \\
\hline 2 & $1.1 \%$ & $48.3 \%$ & $26 \%$ & $8.7 \%$ & 0 & 0 & $15.9 \%$ & $100 \%$ \\
\hline 3 & 0 & $0.6 \%$ & $48.2 \%$ & $26.8 \%$ & $7.8 \%$ & 0 & $16.6 \%$ & $100 \%$ \\
\hline 4 & 0 & 0 & $0.9 \%$ & $49 \%$ & $25.9 \%$ & $9.4 \%$ & $14.8 \%$ & $100 \%$ \\
\hline 5 & $9.2 \%$ & 0 & 0 & $1.1 \%$ & $48.5 \%$ & $25.3 \%$ & $15.9 \%$ & $100 \%$ \\
\hline 6 & $26.8 \%$ & $7.9 \%$ & 0 & 0 & $1.1 \%$ & $48 \%$ & $16.2 \%$ & $100 \%$ \\
\hline
\end{tabular}

Table 4. Percentage of the selected vectors in different sectors of the VSR using the conventional MPC.

\begin{tabular}{ccccccccc}
\hline \multirow{2}{*}{ Sector } & \multicolumn{7}{c}{ Selected Vectors } & \multirow{2}{*}{ Sum } \\
\cline { 2 - 8 } & $\overrightarrow{\boldsymbol{V}}_{1}$ & $\overrightarrow{\boldsymbol{V}}_{2}$ & $\overrightarrow{\boldsymbol{V}}_{3}$ & $\overrightarrow{\boldsymbol{V}}_{4}$ & $\overrightarrow{\boldsymbol{V}}_{5}$ & $\overrightarrow{\boldsymbol{V}}_{6}$ & $\overrightarrow{\boldsymbol{V}}_{7}, \overrightarrow{\boldsymbol{V}}_{8}$ & \\
\hline 1 & $44.1 \%$ & $33.3 \%$ & 0 & 0 & 0 & $3.8 \%$ & $18.8 \%$ & $100 \%$ \\
2 & $1.6 \%$ & $47.2 \%$ & $29.6 \%$ & 0 & 0 & 0 & $21.6 \%$ & $100 \%$ \\
3 & 0 & $1.1 \%$ & $47.4 \%$ & $30.1 \%$ & $0.9 \%$ & 0 & $20.5 \%$ & $100 \%$ \\
4 & 0 & 0 & $3.7 \%$ & $43.8 \%$ & $34.8 \%$ & 0 & $17.7 \%$ & $100 \%$ \\
5 & 0 & 0 & 0 & $0.7 \%$ & $46.5 \%$ & $31.5 \%$ & $21.3 \%$ & $100 \%$ \\
6 & $31 \%$ & $0.2 \%$ & 0 & 0 & $1.2 \%$ & $46.3 \%$ & $21 . \%$ & $100 \%$ \\
\hline \multicolumn{7}{c}{ : adjacent vector. }
\end{tabular}




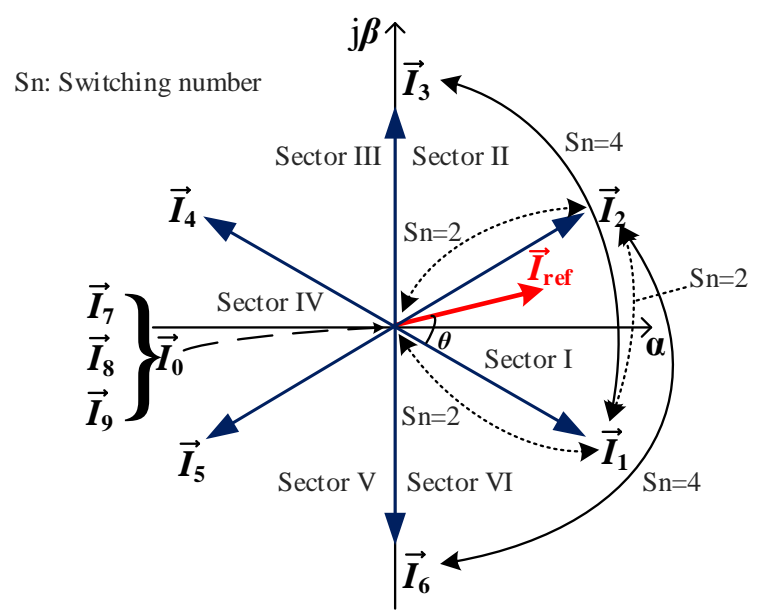

Figure 3. Commutation space vector diagram in sector I of the AC-DC MC.

Table 5. Switching numbers of the commutations between different vectors in different sectors of the AC-DC MC using the conventional MPC.

\begin{tabular}{|c|c|c|c|c|c|c|c|}
\hline \multirow{2}{*}{ Commutations } & \multicolumn{6}{|c|}{ Sector } & \multirow{2}{*}{ Sum } \\
\hline & 1 & 2 & 3 & 4 & 5 & 6 & \\
\hline$\vec{I}_{1}-\vec{I}_{2}$ & 56 & 26 & 0 & 0 & 0 & 4 & 86 \\
\hline$\vec{I}_{1}-\vec{I}_{3}$ & 44 & 2 & 0 & 0 & 0 & 0 & 46 \\
\hline$\vec{I}_{1}-\vec{I}_{4}$ & 0 & 0 & 0 & 0 & 0 & 0 & 0 \\
\hline$\vec{I}_{1}-\vec{I}_{5}$ & 0 & 0 & 0 & 0 & 120 & 0 & 120 \\
\hline$\vec{I}_{1}-\vec{I}_{6}$ & 6 & 0 & 0 & 0 & 0 & 120 & 126 \\
\hline$\vec{I}_{1}-\vec{I}_{0}$ & 46 & 0 & 0 & 0 & 0 & 0 & 46 \\
\hline$\vec{I}_{2}-\vec{I}_{3}$ & 8 & 50 & 0 & 0 & 0 & 0 & 58 \\
\hline$\vec{I}_{2}-\vec{I}_{4}$ & 0 & 8 & 0 & 0 & 0 & 0 & 8 \\
\hline$\vec{I}_{2}-\vec{I}_{5}$ & 0 & 0 & 0 & 0 & 0 & 0 & 0 \\
\hline$\vec{I}_{2}-\vec{I}_{6}$ & 0 & 0 & 0 & 0 & 0 & 104 & 104 \\
\hline$\vec{I}_{2}-\vec{I}_{0}$ & 10 & 42 & 0 & 0 & 0 & 0 & 52 \\
\hline$\vec{I}_{3}-\vec{I}_{4}$ & 0 & 4 & 58 & 0 & 0 & 0 & 62 \\
\hline$\vec{I}_{3}-\vec{I}_{5}$ & 0 & 0 & 88 & 0 & 0 & 0 & 88 \\
\hline$\vec{I}_{3}-\vec{I}_{6}$ & 0 & 0 & 4 & 0 & 0 & 0 & 4 \\
\hline$\vec{I}_{3}-\vec{I}_{0}$ & 0 & 6 & 40 & 0 & 0 & 0 & 46 \\
\hline$\vec{I}_{4}-\vec{I}_{5}$ & 0 & 0 & 4 & 52 & 0 & 0 & 56 \\
\hline$\vec{I}_{4}-\vec{I}_{6}$ & 0 & 0 & 0 & 116 & 0 & 0 & 116 \\
\hline$\vec{I}_{4}-\vec{I}_{0}$ & 0 & 0 & 2 & 24 & 0 & 0 & 26 \\
\hline$\vec{I}_{5}-\vec{I}_{6}$ & 0 & 0 & 0 & 4 & 52 & 0 & 56 \\
\hline$\vec{I}_{5}-\vec{I}_{0}$ & 0 & 0 & 0 & 8 & 48 & 0 & 56 \\
\hline$\vec{I}_{6}-\vec{I}_{0}$ & 0 & 0 & 0 & 2 & 4 & 36 & 42 \\
\hline Sum & 170 & 138 & 196 & 206 & 224 & 264 & 1198 \\
\hline
\end{tabular}

For simplicity, an example is used to explain the details of the proposed algorithm. After three-phase input current references are generated, the input current reference vectors rotate in the stationary frame at an angular velocity $\omega$ given by

$$
\omega=2 \pi f_{i}
$$


where $f_{i}$ is the fundamental frequency of the input AC source, and $\omega$ is the angular frequency of the grid voltage. The angular displacement between the input current reference vector and the stationary frame can be obtained from Reference [25]

$$
\theta(t)=\int_{0}^{t} \omega(t) d t+\theta(0)
$$

Table 6. Switching numbers of the commutations between different vectors in different sectors of the VSR using the conventional MPC.

\begin{tabular}{|c|c|c|c|c|c|c|c|}
\hline \multirow{2}{*}{ Commutations } & \multicolumn{6}{|c|}{ Sector } & \multirow{2}{*}{ Sum } \\
\hline & 1 & 2 & 3 & 4 & 5 & 6 & \\
\hline$\vec{V}_{1}-\vec{V}_{2}$ & 80 & 2 & 0 & 0 & 0 & 4 & 86 \\
\hline$\vec{V}_{1}-\vec{V}_{3}$ & 0 & 0 & 0 & 0 & 0 & 0 & 0 \\
\hline$\vec{V}_{1}-\vec{V}_{4}$ & 0 & 0 & 0 & 0 & 0 & 0 & 0 \\
\hline$\vec{V}_{1}-\vec{V}_{5}$ & 0 & 0 & 0 & 0 & 0 & 0 & 0 \\
\hline$\vec{V}_{1}-\vec{V}_{6}$ & 2 & 0 & 0 & 0 & 0 & 64 & 66 \\
\hline$\vec{V}_{1}-\vec{V}_{0}$ & 66 & 2 & 0 & 0 & 0 & 42 & 110 \\
\hline$\vec{V}_{2}-\vec{V}_{3}$ & 0 & 78 & 4 & 0 & 0 & 0 & 82 \\
\hline$\vec{V}_{2}-\vec{V}_{4}$ & 0 & 0 & 0 & 0 & 0 & 0 & 0 \\
\hline$\vec{V}_{2}-\vec{V}_{5}$ & 0 & 0 & 0 & 0 & 0 & 0 & 0 \\
\hline$\vec{V}_{2}-\vec{V}_{6}$ & 0 & 0 & 0 & 0 & 0 & 8 & 8 \\
\hline$\vec{V}_{2}-\vec{V}_{0}$ & 30 & 62 & 0 & 0 & 0 & 0 & 92 \\
\hline$\vec{V}_{3}-\vec{V}_{4}$ & 0 & 0 & 72 & 10 & 0 & 0 & 82 \\
\hline$\vec{V}_{3}-\vec{V}_{5}$ & 0 & 0 & 0 & 12 & 0 & 0 & 12 \\
\hline$\vec{V}_{3}-\vec{V}_{6}$ & 0 & 0 & 0 & 0 & 0 & 0 & 0 \\
\hline$\vec{V}_{3}-\vec{V}_{0}$ & 0 & 28 & 56 & 0 & 0 & 0 & 84 \\
\hline$\vec{V}_{4}-\vec{V}_{5}$ & 0 & 0 & 2 & 82 & 4 & 0 & 88 \\
\hline$\vec{V}_{4}-\vec{V}_{6}$ & 0 & 0 & 0 & 0 & 0 & 0 & 0 \\
\hline$\vec{V}_{4}-\vec{V}_{0}$ & 0 & 0 & 36 & 52 & 0 & 0 & 88 \\
\hline$\vec{V}_{5}-\vec{V}_{6}$ & 0 & 0 & 0 & 0 & 68 & 0 & 68 \\
\hline$\vec{V}_{5}-\vec{V}_{0}$ & 0 & 0 & 0 & 26 & 68 & 0 & 94 \\
\hline$\vec{V}_{6}-\vec{V}_{0}$ & 2 & 0 & 0 & 0 & 28 & 56 & 86 \\
\hline Sum & 180 & 172 & 170 & 182 & 168 & 174 & 1046 \\
\hline
\end{tabular}

For a given location of the input current reference vector in the space vector plane, various groups of switching states are selected for optimizing the cost function. For example, when the input current reference vector is located in sector I as shown in Figure 3, two adjacent vectors $\vec{I}_{1}$ and $\vec{I}_{2}$ are selected for the cost function to avoid the commutations between non-adjacent vectors. The selection of active and zero vectors depends on the switching number of the changing switching states. In sector I, two adjacent active vectors $\vec{I}_{1}, \vec{I}_{2}$ are selected, which indicates that the switch $S_{p a}$ is always turned on during the sampling period, whereas the switches $S n b$ and $S n c$ are alternately turned on.

Among the three zero vectors, only the zero vector $\vec{I}_{7}$ is related to the switch Spa. Therefore, three switching vectors related to the switch Spa, i.e., the two active vectors $\vec{I}_{1}, \vec{I}_{2}$, and the zero vector $\vec{I}_{7}$, are selected for the cost function computation. The vector selection schemes of the remaining sectors are similar to the selection algorithm in sector $I$. Through this proposed vector selection method, the switching number is reduced in every sector. Furthermore, only three switching states are considered 
for the optimization of the cost function with the proposed scheme. The computation burden of the proposed method is theoretically reduced by $66 \%$, compared with that of the conventional MPC, which has nine switching states. However, the harmonics and ripple are increased, owing to the number of the valid switching states for optimizing the cost function being less than that in the conventional method. Generally, the cost function selects the switching vector, which minimizes the cost function, and applies it to the converter in the next sampling period. This selection scheme of the conventional MPC method may choose the optimal switching vector located outside the optimal sector regarding the location of input current reference vector. For the switching loss reduction purpose of the proposed MPC, the selected switching vector must be located in the optimal sector. Hence, the proposed MPC method selects the most optimal switching vector among only three switching vectors. The optimal switching vector of the proposed MPC may be less optimal than that of the conventional MPC in several sampling periods. Therefore, the harmonics and ripple of the proposed method are slightly higher than that of the conventional method. The possible solution to compensate for the harmonics is to increase the possible switching vectors in each sector by adding several virtual switching vectors. However, this is out of our scope since the proposed method mainly focuses on the switching loss reduction. Table 7 shows all the selected vectors with different locations in the space vector plane.

Table 7. Summary of the selected vectors in different sectors of the proposed MPC for AC-DC MC.

\begin{tabular}{cc}
\hline Sector & Selected Vectors \\
\hline 1 & $\vec{I}_{1}, \vec{I}_{2}, \vec{I}_{7}$ \\
2 & $\vec{I}_{2}, \vec{I}_{3}, \vec{I}_{9}$ \\
3 & $\vec{I}_{3}, \vec{I}_{4}, \vec{I}_{8}$ \\
4 & $\vec{I}_{4}, \vec{I}_{5}, \vec{I}_{7}$ \\
5 & $\vec{I}_{5}, \vec{I}_{6}, \vec{I}_{9}$ \\
6 & $\vec{I}_{6}, \vec{I}_{1}, \vec{I}_{8}$ \\
\hline
\end{tabular}

\subsection{Cost Function}

In the AC-DC MC, the source currents are controlled. Thus, the cost function computes the errors in the source currents compared with the references. At every sampling period, the control scheme selects the optimal switching state among all the possible switching states and then applies it to the AC-DC MC in the next sampling interval.

To reduce the computation burden further, the Clark transformation is adapted to the AC current and voltage vectors as follows:

$$
\left[\begin{array}{l}
x_{\alpha} \\
x_{\beta}
\end{array}\right]=\left[\begin{array}{ccc}
\frac{2}{3} & \frac{-1}{3} & \frac{-1}{3} \\
0 & \frac{\sqrt{3}}{3} & \frac{-\sqrt{3}}{3}
\end{array}\right]\left[\begin{array}{l}
x_{a} \\
x_{b} \\
x_{c}
\end{array}\right]
$$

where the vector $\left[\begin{array}{ll}x_{\alpha} & x_{\beta}\end{array}\right]^{T}$ represents the space vector plane, and the vector $\left[x_{a} x_{b} x_{c}\right]^{T}$ represents the three-phase source current and voltage vectors.

The cost function of the proposed MPCC with vector selection is expressed as

$$
g=\left|i_{s \alpha}^{*}-i_{s \alpha}(k+1)\right|^{2}+\left|i_{s \beta}^{*}-i_{s \beta}(k+1)\right|^{2}
$$

where $i_{s \alpha}^{*}$ and $i_{s \beta}^{*}$ are the source current references in the stationary frame. 


\subsection{Delay Compensation}

The calculation time in a practical system when constructing the predictive algorithm controller must be strictly considered owing to the time required to compute all the possible switching states. This may lead to errors in the real system when the predictive control scheme is implemented.

At the time $k$, the controller selects the optimized switching state to be applied at time $k+1$. It is necessary to predict all possible future behaviors of the source currents one step forward at time $k+2$ to avoid any delay error, as follows:

$$
i_{S}(k+2)=c_{1} v_{S}(k+1)+c_{2} v_{i}(k+1)+c_{3} i_{S}(k+1)+c_{4} i_{i}(k+1)
$$

If the sampling period is small, the source and input voltages can be considered constant during the sampling period and are given by

$$
\begin{aligned}
& v_{\mathcal{S}}(k+1) \approx v_{\mathcal{S}}(k) \\
& v_{i}(k+1) \approx v_{i}(k)
\end{aligned}
$$

where

$$
\Delta \theta=\omega T_{s}
$$

The cost function of the proposed method with delay compensation is expressed as

$$
g=\left|i_{s \alpha}^{*}-i_{s \alpha}(k+2)\right|^{2}+\left|i_{s \beta}^{*}-i_{s \beta}(k+2)\right|^{2}
$$

\subsection{Controller System}

The control block diagram of the proposed scheme is presented in Figure 4. The DC voltage at the output terminal is compared with its reference. A proportional-integral (PI) controller is used to obtain the current reference amplitude, and the $\mathrm{dq}-\alpha \beta$ transformation combined with the angle obtained from the source voltages is used to formulate the source current references.

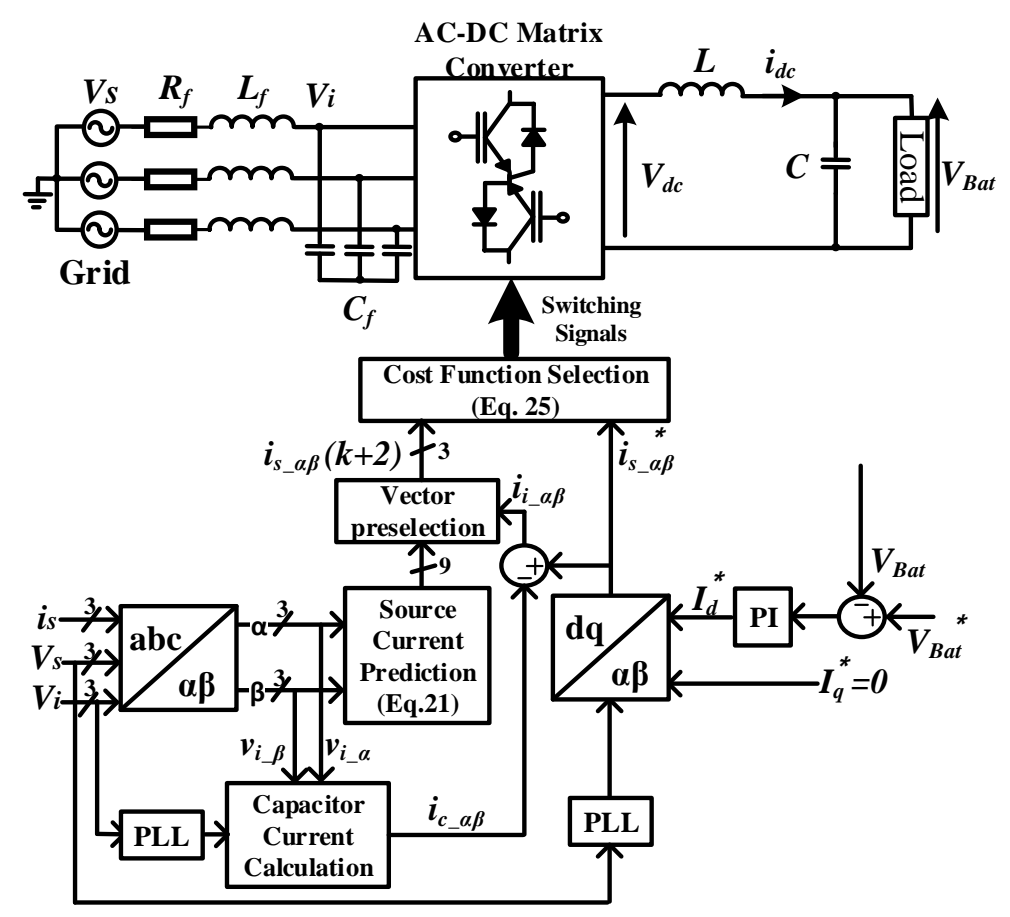

Figure 4. Control diagram scheme of the proposed MPCC with vector selection for the AC-DC MC. 
The three-phase voltages, three-phase currents, and three-phase input voltages are sensed and used for current prediction and capacitor current calculation at the AC source. The selection angle is obtained from the input current and then used for vector selection.

\section{Verification of the Proposed Strategy}

\subsection{Simulation Results}

Simulation results are demonstrated with the parameters in Table 8 using PSIM software to confirm the effectiveness of the proposed strategy. Figure 5 presents the simulation results of the conventional MPC (Figure 5a) and the proposed MPCC (Figure 5b), including A-phase source voltage, three-phase source currents, and the switching signal of the switch $S_{p a}$. It is evident that both control strategies can correctly operate with high-quality sinusoidal source currents. Furthermore, unity-power-factor operation is guaranteed in the AC source under the conventional and proposed methods. The proposed method is based on the location of the input current reference vector to select the optimal switching vector among three possible switching vectors. Since the location of the input current reference vector is obtained from the input currents, there is a small displacement angle between the source currents and the input currents owing to the input capacitor current. Therefore, there is a small displacement angle between the switching signal and the source currents.

Table 8. Parameters of the AC-DC MC.

\begin{tabular}{cc}
\hline Parameters & Value \\
\hline Source phase voltage $\left(v_{s}\right)$ & $100 \mathrm{~V}$ \\
Source frequency $\left(\mathrm{f}_{\mathrm{i}}\right)$ & $60 \mathrm{~Hz}$ \\
Input filter inductance $\left(\mathrm{L}_{\mathrm{f}}\right)$ & $5 \mathrm{mH}$ \\
Input filter capacitance $\left(\mathrm{C}_{\mathrm{f}}\right)$ & $60 \mu \mathrm{F}$ \\
Input filter resistance $\left(\mathrm{R}_{\mathrm{f}}\right)$ & $0.1 \Omega$ \\
Output filter inductance $(L)$ & $2 \mathrm{mH}$ \\
Output filter capacitance $(C)$ & $40 \mu \mathrm{F}$ \\
Load resistance $(R)$ & $20 \Omega$ \\
Sampling frequency $\left(\mathrm{f}_{\mathrm{s}}\right)$ & $40 \mathrm{kHz}$ \\
Load voltage reference $\left(\mathrm{V}_{\mathrm{Bat}}\right)$ & $100 \mathrm{~V}$ \\
\hline
\end{tabular}
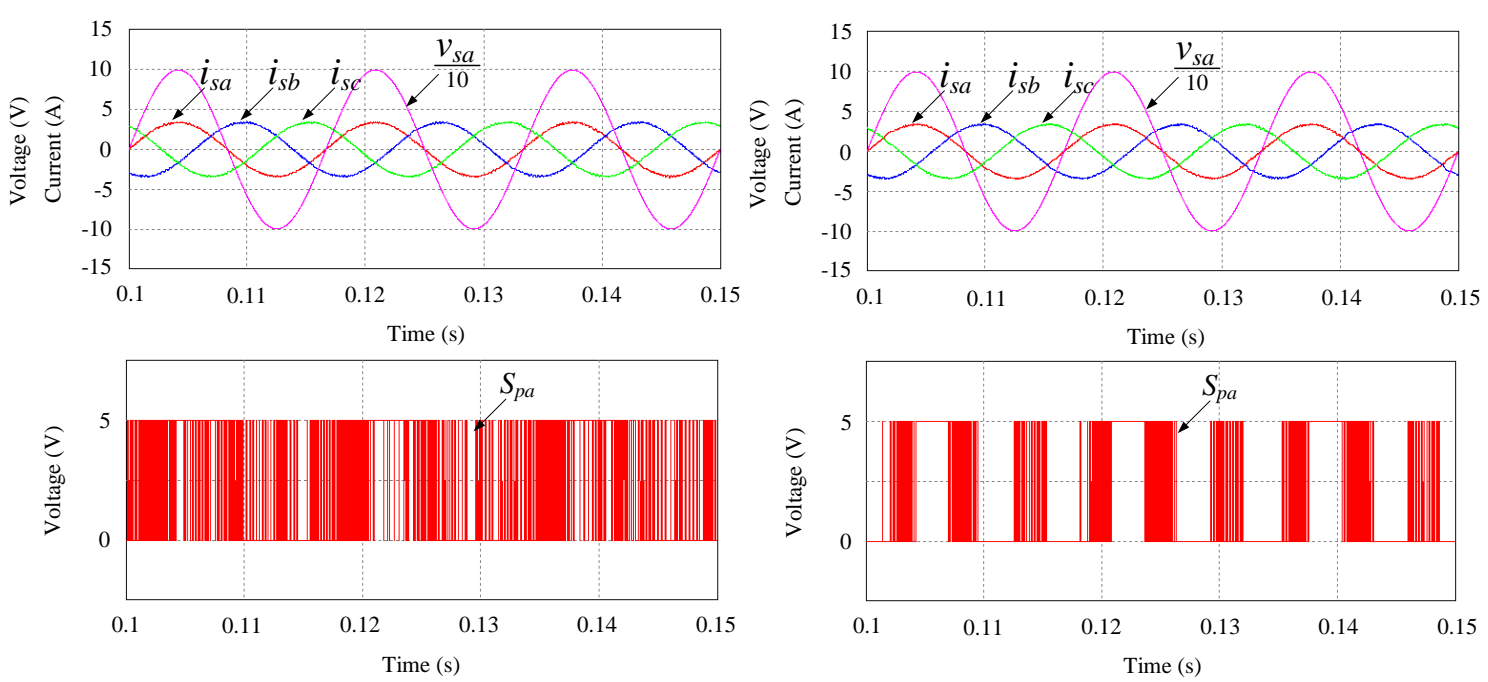

(a)

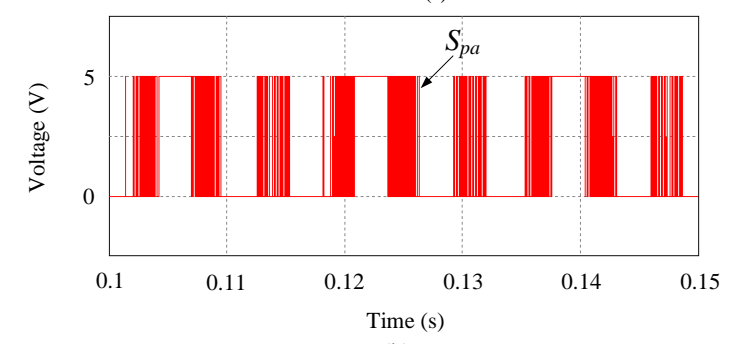

(b)

Figure 5. Three-phase source currents, A-phase source voltage, and switching signal of $S_{p a}$ under different control strategies: (a) Conventional MPC (b) proposed MPCC.

This displacement angle varies with the size of the input filter capacitor and has no negative effect on the overall performance of the AC-DC MC. The switch $S_{p a}$ is successfully clamped during sector 
I while maintaining the same performance of the converter under the proposed control strategy as that under the conventional control strategy. The total harmonic distortion (THD) of the A-phase source current under the conventional and proposed MPCs is illustrated in Figure 6. The THD of the proposed MPC is higher than that of the conventional MPC owing to the reduction in the number of possible switching states for cost function consideration at every sampling period. Generally, this is a trade-off between the reduction of switching loss and the increase of current distortion. Figures 7 and 8 present the DC currents and load voltages of the conventional and proposed methods, respectively. It is observed that both the control strategies produce pure DC waveforms and accurately track their load voltage reference at $100 \mathrm{~V}$. The transient states of the conventional and proposed strategies are illustrated in Figures 9-11. It is evident from Figure 9 that smooth sinusoidal source currents and unity power factor in the transient state are guaranteed by both the conventional and proposed methods. In addition, DC currents and load voltages accurately and quickly track their references when the input currents vary from $3 \mathrm{~A}$ to $4.5 \mathrm{~A}$, as shown in Figures 10 and 11. Both the control strategies work correctly under the steady and transient states.

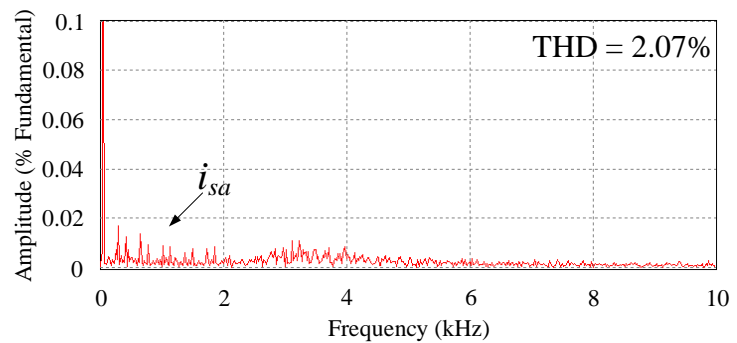

(a)

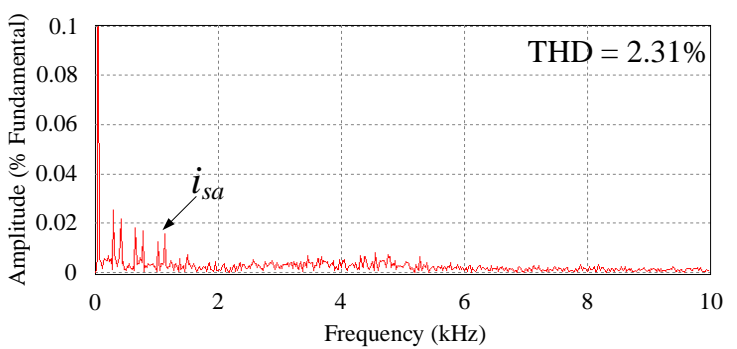

(b)

Figure 6. Fast Fourier transform analysis of the A-phase source current under different control strategies: (a) Conventional MPC (b) proposed MPCC.

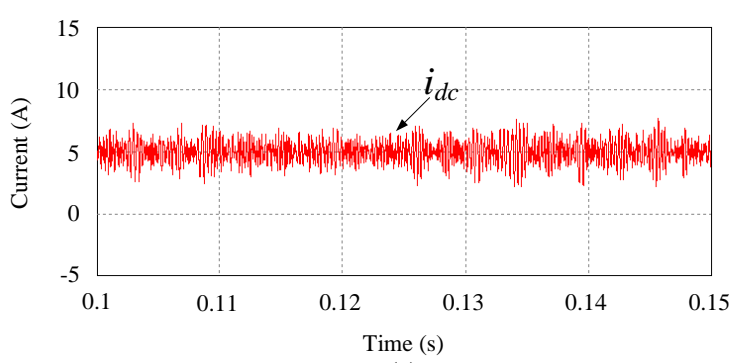

(a)

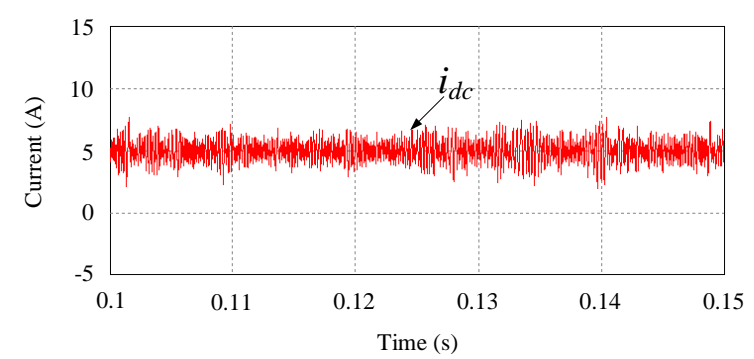

(b)

Figure 7. DC current under different control strategies: (a) Conventional MPC (b) proposed MPCC.

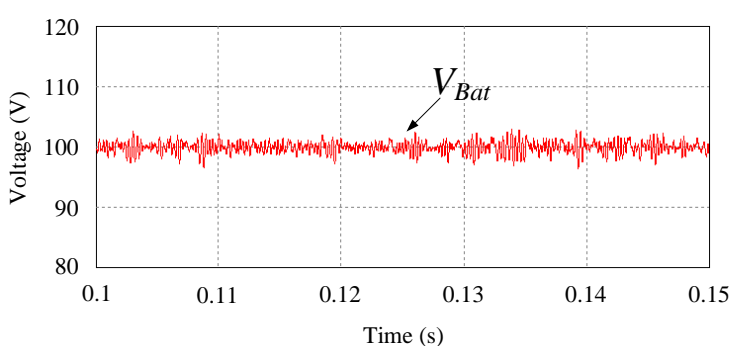

(a)

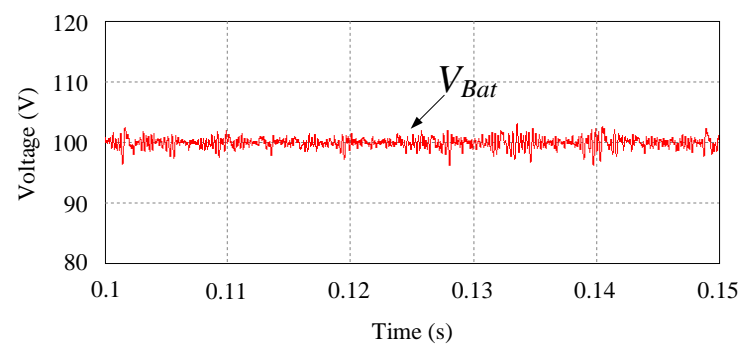

(b)

Figure 8. Load voltage under different control strategies: (a) Conventional MPC (b) proposed MPCC. 


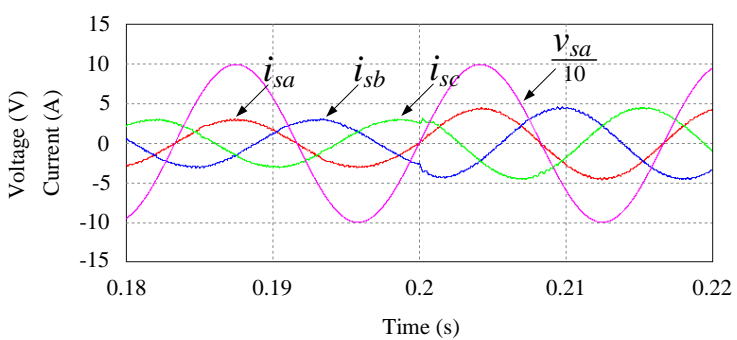

(a)

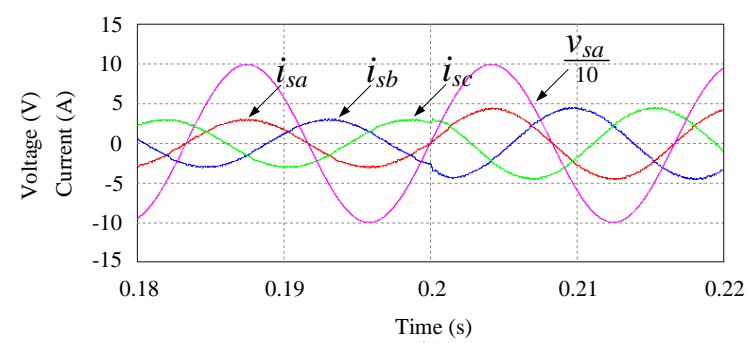

(b)

Figure 9. Transient response of the three-phase source current and the A-phase source voltage under different control strategies: (a) Conventional MPC (b) proposed MPCC.

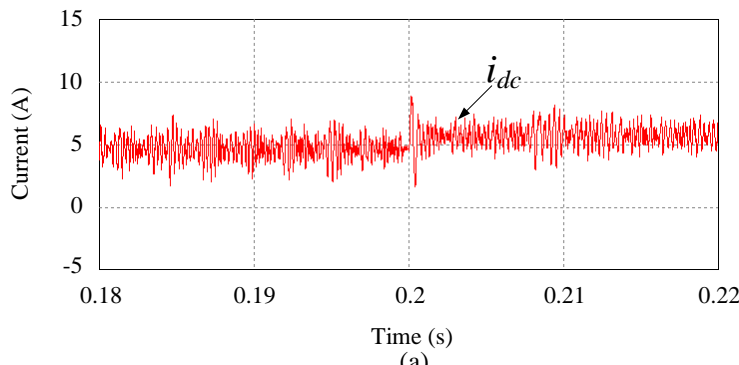

(a)

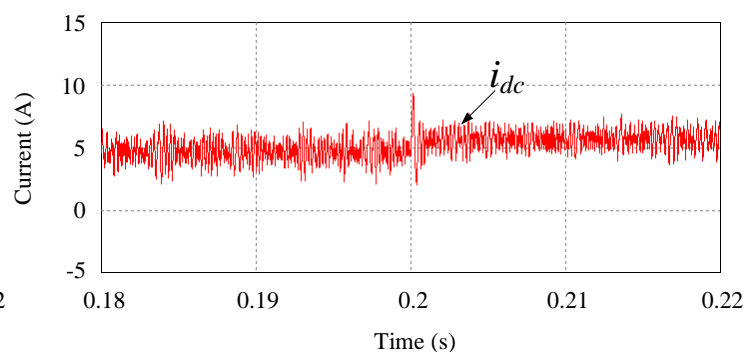

(b)

Figure 10. Transient response of the DC current under different control strategies: (a) Conventional MPC (b) proposed MPCC.

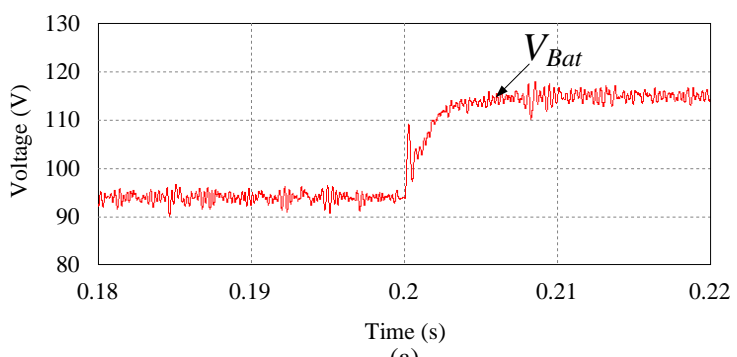

(a)

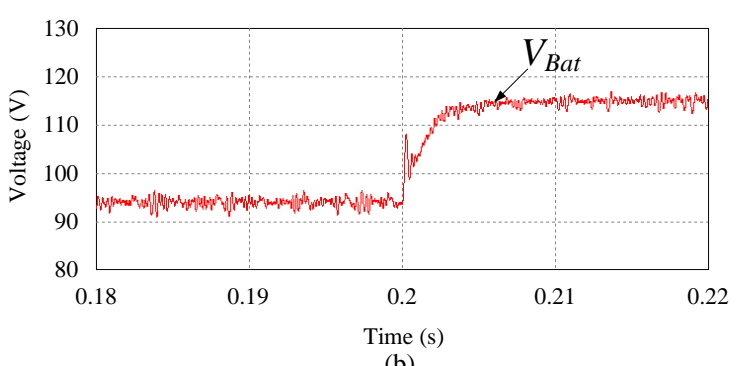

(b)

Figure 11. Transient response of the load voltage under different control strategies: (a) Conventional MPC (b) proposed MPCC.

Table 9 summarizes the vector selection in different sectors of the proposed method in one current period. From a comparison with Table 1, it is evident that the proposed strategy selects only three vectors in each sector correctly, whereas the conventional strategy selects five vectors for each sector. The total number of vector selections of the conventional and proposed MPCs are almost the same. Tables 10 and 11 present the number of switchings of different switches in different sectors under the conventional and proposed strategies. In the proposed MPC, three switches in the lower arm and upper arm are alternately operated in odd and even sectors, respectively. The switches $S_{p a}, S_{n c}, S_{p b}$, $S_{n a}, S_{p c}$, and $S_{n b}$ are respectively clamped in sectors I, II, II, IV, V, and VI, as evident from Table 9. The total number of switchings in different sectors of the proposed method is lower than that of the conventional method by $24.4 \%$. The reduction in the switching number results in the reduction of switching loss under the proposed control strategy as well as reduction in the thermal stresses in the power switches; thus, the lifetimes of bidirectional switches will be prolonged compared with those under the conventional strategy. 
Table 9. Summary of vector selection in different sectors of the proposed MPC.

\begin{tabular}{ccccccccc}
\hline \multirow{2}{*}{ Sector } & \multicolumn{7}{c}{ Selected vectors } & \multirow{2}{*}{ Sum } \\
\cline { 2 - 7 } & $\overrightarrow{\boldsymbol{I}}_{1}$ & $\overrightarrow{\boldsymbol{I}}_{2}$ & $\overrightarrow{\boldsymbol{I}}_{3}$ & $\overrightarrow{\boldsymbol{I}}_{4}$ & $\overrightarrow{\boldsymbol{I}}_{5}$ & $\overrightarrow{\boldsymbol{I}}_{6}$ & $\overrightarrow{\boldsymbol{I}}_{7}, \overrightarrow{\boldsymbol{I}}_{8}, \overrightarrow{\boldsymbol{I}}_{9}$ & \\
\hline 1 & 45.3 & 38.2 & 0 & 0 & 0 & 0 & 27.3 & 110.8 \\
2 & 0 & 45.8 & 38.3 & 0 & 0 & 0 & 27.5 & 111.6 \\
3 & 0 & 0 & 45 & 38.5 & 0 & 0 & 27.5 & 111 \\
4 & 0 & 0 & 0 & 45 & 38.5 & 0 & 28.2 & 111.7 \\
5 & 0 & 0 & 0 & 0 & 45 & 38 & 28 & 111 \\
6 & 37.5 & 0 & 0 & 0 & 0 & 45.8 & 28.2 & 111.5 \\
Sum & 82.8 & 84 & 83.3 & 83.5 & 83.5 & 83.8 & 166.7 & 667.6 \\
\hline
\end{tabular}

Table 10. Number of switchings in different sectors of different switches under the conventional MPC.

\begin{tabular}{|c|c|c|c|c|c|c|c|}
\hline \multirow{2}{*}{ Sector } & \multicolumn{6}{|c|}{ Number of Switching } & \multirow{2}{*}{ Sum } \\
\hline & $s_{p a}$ & $S_{p b}$ & $S_{p c}$ & $S_{n a}$ & $S_{n b}$ & $S_{n c}$ & \\
\hline 1 & 12 & 12 & 0 & 13 & 35 & 27 & 99 \\
\hline 2 & 31 & 32 & 0 & 25 & 0 & 25 & 113 \\
\hline 3 & 18 & 24 & 8 & 37 & 0 & 36 & 123 \\
\hline 4 & 7 & 33 & 29 & 15 & 16 & 0 & 100 \\
\hline 5 & 23 & 0 & 23 & 26 & 26 & 0 & 98 \\
\hline 6 & 33 & 0 & 33 & 12 & 22 & 10 & 110 \\
\hline Sum & 124 & 101 & 93 & 128 & 99 & 98 & 643 \\
\hline
\end{tabular}

Table 11. Number of switchings in different sectors of different switches under the proposed MPCC.

\begin{tabular}{|c|c|c|c|c|c|c|c|}
\hline \multirow{2}{*}{ Sector } & \multicolumn{6}{|c|}{ Number of Switching } & \multirow{2}{*}{ Sum } \\
\hline & $S_{p a}$ & $S_{p b}$ & $s_{p c}$ & $S_{n a}$ & $S_{n b}$ & $S_{n c}$ & \\
\hline 1 & 0 & 0 & 0 & 25 & 31 & 25 & 81 \\
\hline 2 & 33 & 26 & 26 & 0 & 0 & 0 & 85 \\
\hline 3 & 0 & 0 & 0 & 26 & 25 & 33 & 84 \\
\hline 4 & 21 & 29 & 25 & 0 & 0 & 0 & 75 \\
\hline 5 & 0 & 0 & 0 & 31 & 25 & 23 & 79 \\
\hline 6 & 25 & 24 & 33 & 0 & 0 & 0 & 82 \\
\hline Sum & 79 & 79 & 84 & 82 & 81 & 81 & 486 \\
\hline
\end{tabular}

The switching losses of bidirectional switches depend on the current and voltage related to the process of commutation. The total loss of a bidirectional switch is determined as follows:

$$
P_{\text {total }}=P_{\text {cond }}+P_{\text {swit }}
$$

where $P_{\text {cond }}$ is the conduction loss and $P_{\text {swit }}$ is the switching loss of the bidirectional switch.

The conduction loss is given by

$$
P_{\text {cond }}=\frac{1}{T_{s}} \int\left(V_{C E} * I_{C}\right) d t
$$

where $V_{C E}$ and $I_{C}$ are the switched voltage and current, respectively.

The switching losses of a bidirectional switch are the sum of all turn-on and turn-off energies expressed as

$$
P_{\text {swit }}=P_{o n}+P_{o f f}=\frac{1}{T_{s}} \sum E_{o n}+\frac{1}{T_{s}} \sum E_{o f f}
$$

where $E_{o n}$ is the turn-on energy and $E_{o f f}$ is the turn-off energy of the bidirectional switch. 
The total losses of the bidirectional switches under the conventional and proposed methods for different sampling frequencies are illustrated in Figure 12. As it can be seen from Figure 12, the switching loss for different sampling frequencies of the proposed MPC is always lower than that of the conventional MPC by approximately $21.8 \%$ to $23.9 \%$. Figure 13 illustrates the switching number of the conventional and proposed strategies for different sampling frequencies. It is evident that the number of switchings in the proposed method is less than that in the conventional method, which results in the reduction of switching loss.

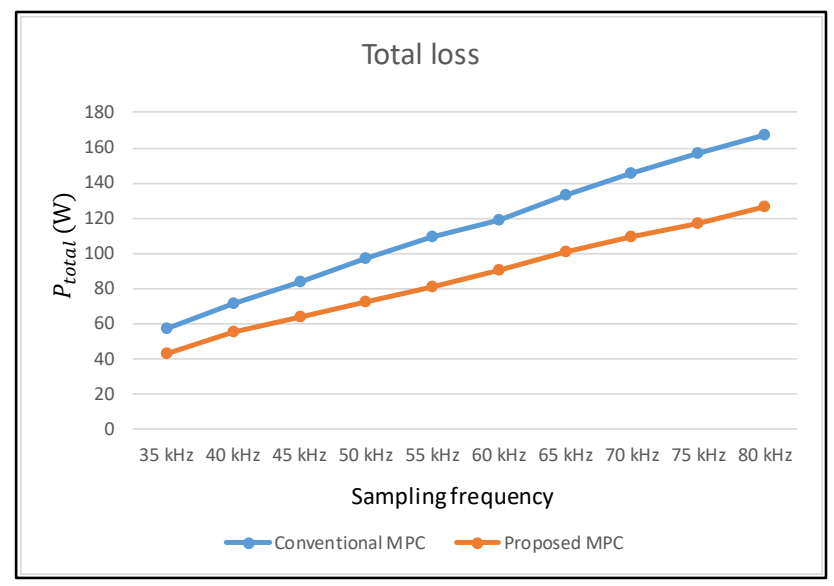

Figure 12. Total losses of the bidirectional switches versus sampling frequency under the conventional and proposed strategies.

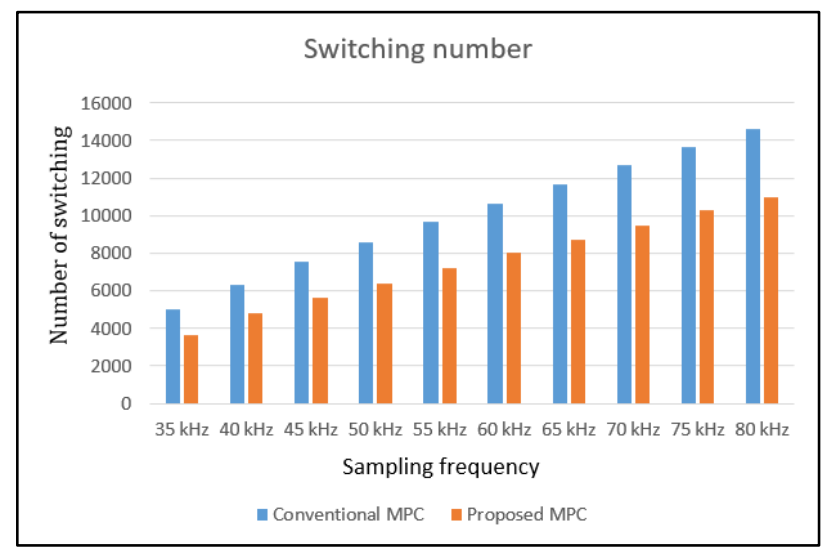

Figure 13. Switching number of the bidirectional switches versus sampling frequency under the conventional and proposed control strategies.

Figure 14 presents the switching loss versus sampling frequency under the conventional and proposed strategies. The total losses of the bidirectional switches mainly depend on the switching losses. The proposed method successfully reduces the switching losses considerably compared with the conventional method in a wide range of sampling frequencies. The THD versus sampling frequency under the conventional and proposed MPCs is shown in Figure 15. Because the reduction in the number of possible switching states for consideration of the cost function, the THD of the proposed method is slightly higher than that of the conventional method. The simulation results show the effectiveness of the proposed method in reducing the switching loss compared with that of the conventional strategy. 


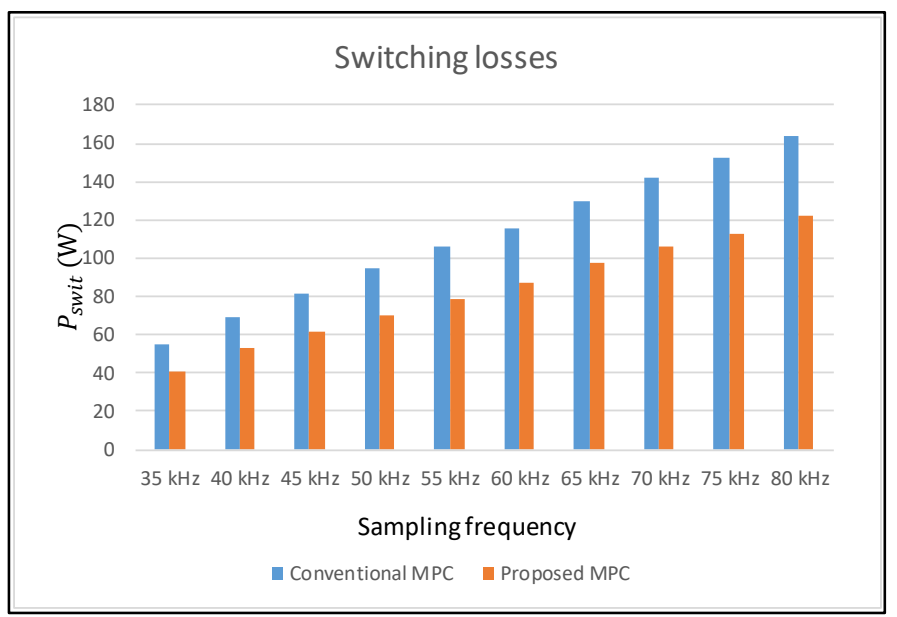

Figure 14. Switching loss of the bidirectional switches versus sampling frequency under the conventional and proposed control strategies.

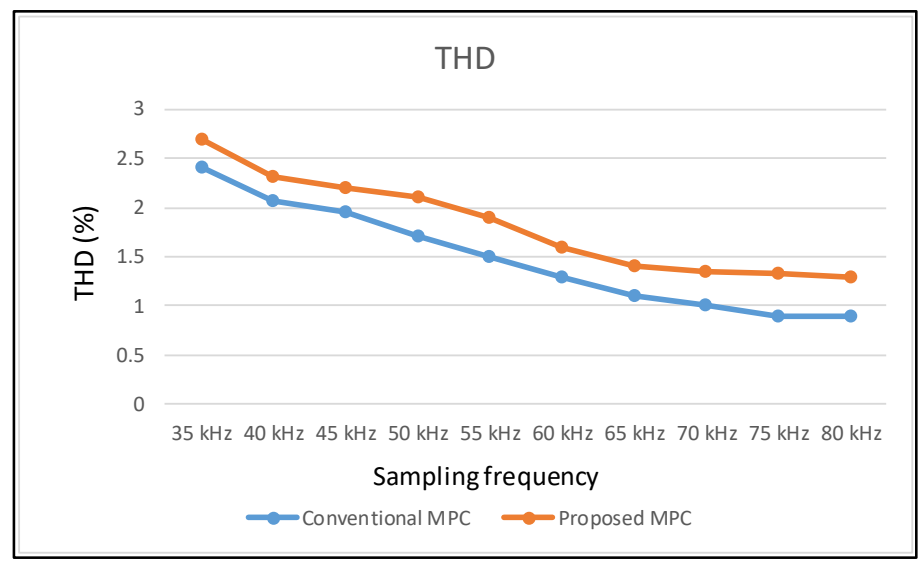

Figure 15. Total harmonic distortion (THD) versus sampling frequency under the conventional and proposed control strategies.

\subsection{Experimental Results}

An AC-DC MC was built with six bidirectional power devices, constructed with two IGBT modules (IXA37IF1200HJ) with a common emitter connected in series, to validate the effectiveness of the proposed MPCC with vector selection. The proposed strategy is executed on a Texas Instruments digital signal processor board (TI TMS320F28335). The parameters of the experiments are indicated in Table 8. Figure 16 presents the waveforms of the A-phase source current, A-phase source voltage, DC current, and load voltage of the conventional and proposed MPCs. Both strategies correctly produce DC waveforms and accurately track the load voltage reference at $100 \mathrm{~V}$. The converter operation under unity-power-factor condition is thus guaranteed by the conventional and proposed methods. Figure 17 shows the waveforms of the A-phase source voltage, A-phase source current, load voltage, and DC current of the AC-DC MC in transient state when the input currents vary from $3 \mathrm{~A}$ to $4.5 \mathrm{~A}$ under the conventional and proposed MPCs. The unity-power-factor operation is guaranteed, and smooth and sinusoidal current waveforms are obtained. Figure 18 presents the THD of the A-phase source current, A-phase source voltage, and the switching signal of the A-phase upper-arm switch. It is clearly seen that the proposed strategy successfully clamps the switch from performing a switching operation during every sampling period when the current reference is located in sector I. Furthermore, the total efficiency of the AC-DC MC obtained using a precision power analyzer (PPA5500) model under the proposed control strategy is $91.2 \%$, whereas that of the conventional control strategy is $89.7 \%$. The effectiveness of the proposed method is thus confirmed by the improved efficiency compared with that 
of the conventional MPC. The THD of the proposed MPCC is higher than that of the conventional MPC owing to the reduced number of switching states, as the cost function of the proposed method is lower than that of the conventional MPC.

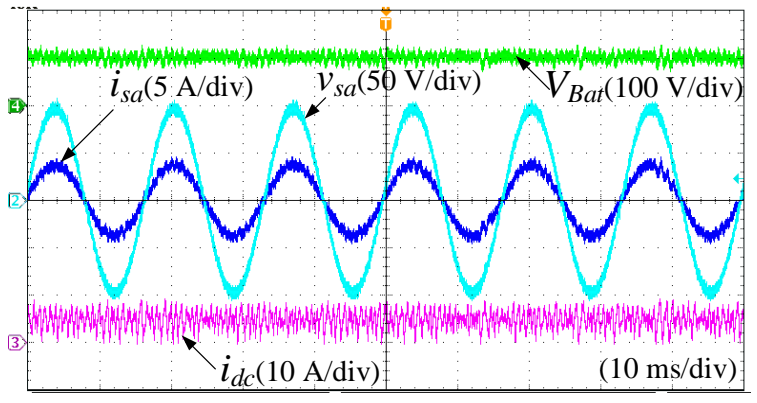

(a)

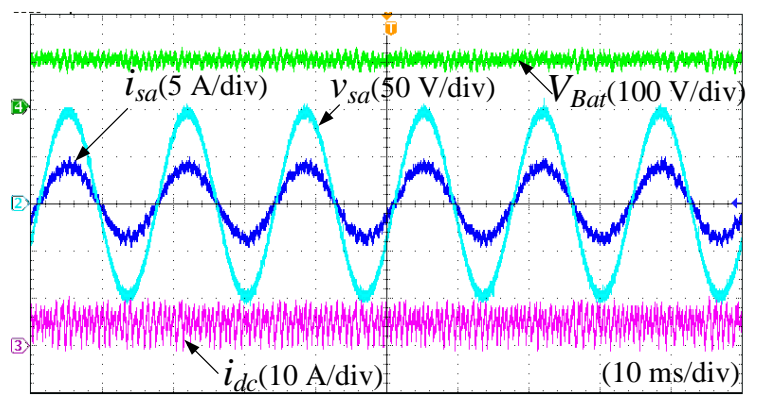

(b)

Figure 16. Waveforms of A-phase source voltage, A-phase source current, load voltage, and DC current at steady state under different control strategies: (a) Conventional MPC (b) proposed MPCC.

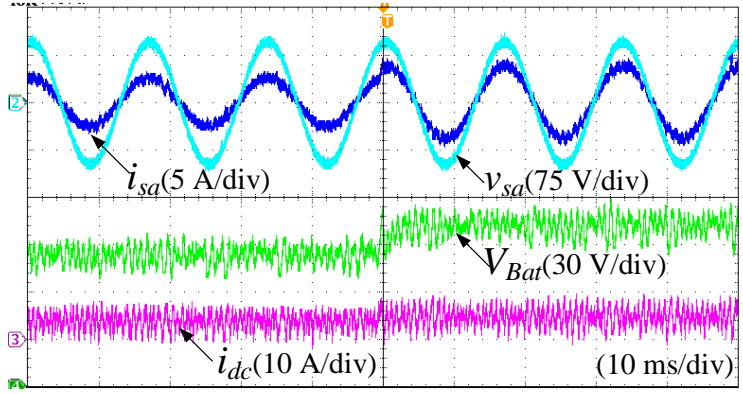

(a)

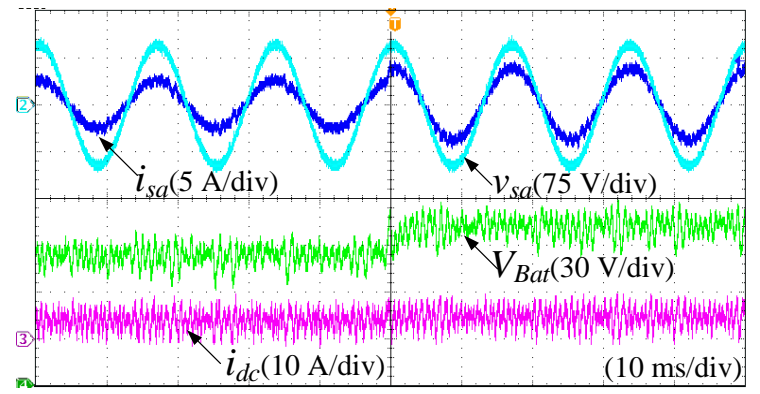

(b)

Figure 17. Waveforms of A-phase source voltage, A-phase source current, load voltage, and DC current at transient state under different control strategies: (a) Conventional MPC (b) proposed MPCC.

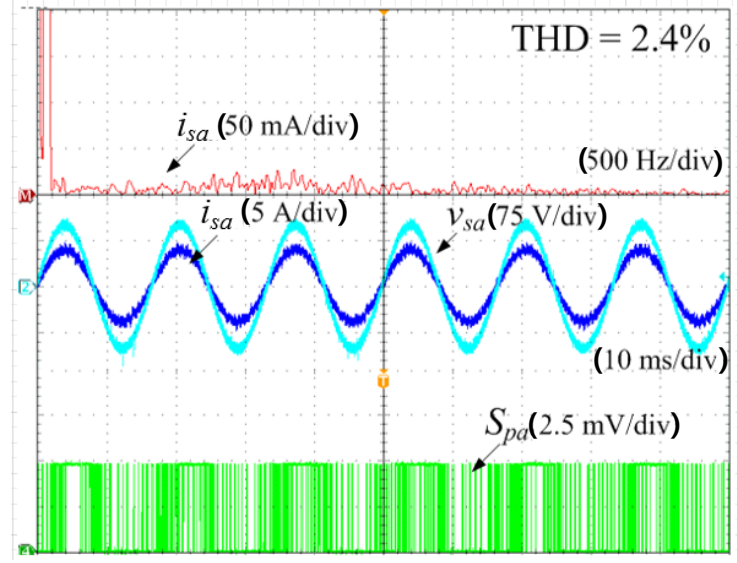

(a)

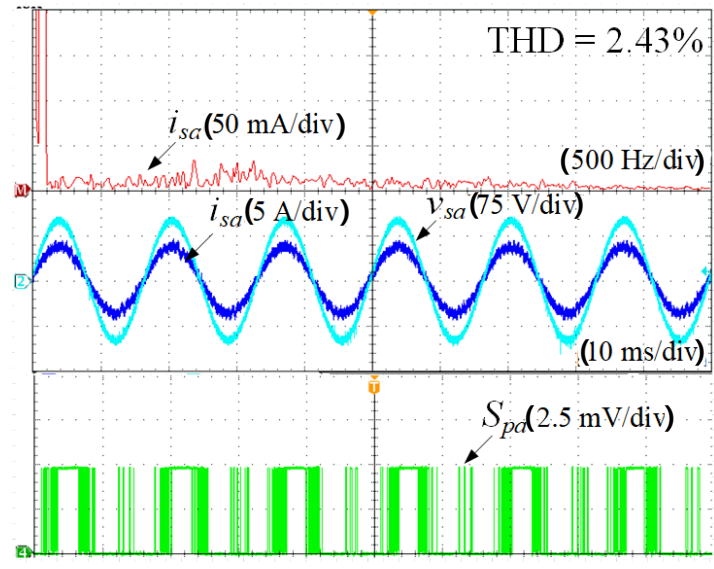

(b)

Figure 18. Experimental waveforms of A-phase source voltage, A-phase source current, THD of A-phase source current, and switching signal of A-phase upper-arm switch under different control strategies: (a) Conventional MPC (b) proposed MPCC.

\section{Conclusions}

In this paper, an MPCC scheme for an AC-DC MC with vector selection is proposed. The proposed method successfully reduces switching loss while guaranteeing good performance of the AC-DC MC in both steady- and transient-state conditions compared with the conventional method by clamping three switches to stop performing the switching operation during every sampling period. The total 
efficiency of the converter is increased to $91.2 \%$ by the proposed strategy compared with that of the conventional strategy (89.7\%). Further, unity-power-factor operation is guaranteed, and smooth and sinusoidal current waveforms are obtained. The THD of the proposed method is slightly higher than that of the conventional method. This is a trade-off between the reduction in the switching loss and the increase of the THD. The validity of the proposed MPC is confirmed by the simulation and experimental results. Future research work will be aimed at improving the performance of the AC-DC MC while maintaining the effectiveness of the proposed method.

Author Contributions: Conceptualization, S.K.; Data curation, E.-S.J.; Funding acquisition, S.K.; Investigation, E.-S.J. and H.-L.D.; Methodology, S.K.; Project administration, S.K.; Resources, S.K.; Software, E.-S.J.; Supervision, S.K.; Validation, E.-S.J.; Writing—original draft, H.-L.D.

Funding: This research was supported by the National Research Foundation of Korea (NRF) grant funded by the Korean government (MSIP) (2017R1A2B4011444) and by the Chung-Ang University research grant in 2018.

Conflicts of Interest: The authors declare no conflict of interest.

\section{References}

1. Rivera, M.; Rodriguez, J.; Wheeler, P.W.; Rojas, C.A.; Wilson, A.; Espinoza, J.R. Control of a matrix converter with imposed sinusoidal source currents. IEEE Trans. Ind. Electron. 2012, 59, 1939-1949. [CrossRef]

2. Vargas, R.; Ammann, U.; Rodriguez, J. Predictive approach to increase efficiency and reduce switching losses on matrix converters. IEEE Trans. Power Electron. 2009, 24, 894-902. [CrossRef]

3. Rivera, M.; Rodriguez, J.; Espinoza, J.R.; Friedli, T.; Kolar, J.W.; Wilson, A.; Rojas, C.A. Imposed sinusoidal source and load currents for an indirect matrix converter. IEEE Trans. Ind. Electron. 2012, 59, 3427-3435. [CrossRef]

4. Rodriguez, J.; Rivera, M.; Kolar, J.W.; Wheeler, P.W. A review of control and modulation method for matrix converters. IEEE Trans. Ind. Electron. 2012, 59, 58-70. [CrossRef]

5. Yang, X.J.; Cai, W.; Ye, P.S.; Gong, Y.M. Research on dynamic characteristics of matrix rectifier. In Proceedings of the 2006 1st IEEE Conference on Industrial Electronics and Applications, Singapore, 24-26 May 2006.

6. Vazquez, S.; Lukic, S.M.; Galvan, E.; Franquelo, L.G.; Carrasco, J.M. Energy storage systems for transport and grid applications. IEEE Trans. Ind. Electron. 2010, 57, 3881-3895. [CrossRef]

7. Yilmaz, M.; Krein, P. Review of battery charger topologies, charging power levels and infrastructure for plug-in electric and hybrid vehicles. IEEE Trans. Power Electron. 2013, 28, 2151-2169. [CrossRef]

8. Bhuiyan, F.A.; Yazdani, A. Energy storage technologies for grid connected and off-grid power system applications. IEEE Elect. Power Energy Conf. (EPEC) 2012, 28, 2151-2169.

9. Rodriguez, J.R.; Dixon, J.W.; Espinoza, J.R.; Pontt, J.; Lezana, P. PWM regenerative rectifiers: State of the art. IEEE Trans. Ind. Electron. 2005, 52, 5-22. [CrossRef]

10. Ratanapanachote, S.; Cha, H.J.; Enjeti, P.N. A digitally controlled switch mode power supply based on matrix converter. IEEE Trans. Power Electron. 2006, 21, 124-130. [CrossRef]

11. Metidji, R.; Metidji, B.; Mendil, B. Design and implementation of unity power factor fuzzy battery charger using ultra sparse matrix rectifier. IEEE Trans. Power Electron. 2013, 28, 2269-2276. [CrossRef]

12. Feng, B.; Lin, H.; Wang, X. Modulation and control of ac/dc matrix converter for battery energy storage application. IET Power Electron. 2015, 8, 1583-1594. [CrossRef]

13. Feng, B.; Lin, H.; Hu, S.; An, X.; Wang, X. Control strategy of AC-DC matrix converter in battery energy storage system. In Proceedings of the 2012 IEEE Energy Conversion Congress and Exposition (ECCE), Raleigh, NC, USA, 15-20 September 2012.

14. Feng, B.; Lin, H.; Wang, X. Switching losses reduced modulation strategies for ac-dc matrix converter. In Proceedings of the IECON 2013-39th Annual Conference of the IEEE Industrial Electronics Society, Vienna, Austria, 10-13 November 2013; pp. 4961-4966.

15. Feng, B.; Lin, H.; Wang, X.; An, X.; Liu, B. Optimal zero-vector configuration for space vector modulated AC-DC matrix converter. In Proceedings of the 2012 IEEE Energy Conversion Congress and Exposition (ECCE), Raleigh, NC, USA, 15-20 September 2012; pp. 291-297.

16. Su, M.; Wang, H.; Sun, Y.; Yang, J.; Xiong, W.; Liu, Y. AC/DC matrix converter with an optimized modulation strategy for V2G applications. IEEE Trans. Power Electron. 2013, 28, 5736-5745. [CrossRef] 
17. Kim, J.; Kwak, S.; Kim, T. Power factor control method based on virtual capacitor for three-phase matrix rectifiers. IEEE Access 2019, 7, 12484-12494. [CrossRef]

18. Cortes, P.; Kazmierkowski, M.P.; Kennel, R.M.; Quevedo, D.E.; Rodriguez, J. Predictive control in power electronics and drives. IEEE Trans. Ind. Electron. 2008, 55, 4312-4324. [CrossRef]

19. Rodriguez, J.; Kazmierkowski, M.P.; Espinoza, J.R.; Zanchetta, P.; Abu-Rub, H.; Young, H.A.; Rojas, C.A. State of the art of finite control set model predictive control in power electronics. IEEE Trans. Ind. Inf. 2013, 9, 1003-1016. [CrossRef]

20. Nguyen, T.; Lee, H. An enhanced control strategy for ac/dc matrix converters under unbalanced grid voltage. IEEE Trans. Ind. Electron. 2020, 67, 1718-1727. [CrossRef]

21. Nguyen, T.; Lee, H. Simplified model predictive control for ac/dc matrix converters with active damping function under unbalanced grid voltage. IEEE J. Emerg. Sel. Topics Power Electron. 2019. [CrossRef]

22. Gokdag, M.; Gulbudak, O. Model predictive control of ac-dc matrix converter with unity input power factor. In Proceedings of the 2018 IEEE 12th International Conference on Compatibility, Power Electronics and Power Engineering (CPE-POWERENG 2018), Doha, Qatar, 10-12 April 2018.

23. Muller, S.; Ammann, U.; Rees, S. New time-discrete modulation scheme for matrix converters. IEEE Trans. Ind. Electron. 2005, 52, 1607-1615. [CrossRef]

24. Bernet, S.; Ponnaluri, S.; Teichmann, R. Design and loss comparison of matrix converters and voltage source converters for modern AC drives. IEEE Trans. Ind. Electron. 2002, 49, 304-314. [CrossRef]

25. Wu, B. High-Power Converter and AC Drives, 1st ed.; John Wiley \& Sons, Inc.: Hoboken, NJ, USA, 2006.

(C) 2019 by the authors. Licensee MDPI, Basel, Switzerland. This article is an open access article distributed under the terms and conditions of the Creative Commons Attribution (CC BY) license (http://creativecommons.org/licenses/by/4.0/). 